\title{
H19/Igf2 Expression and Methylation of Histone 3 in Mice Chimeric Blastocysts
}

\author{
Maryam Salimi ${ }^{1}$, Abolfazl Shirazi*2,3, Mohsen Norouzian*1, \\ Ameneh Jafari ${ }^{4}$, Haleh Edalatkhah ${ }^{2}$, Maryam Mehravar ${ }^{2}$, \\ Mohammad Majidi ${ }^{5}$, Mohammad Mahdi Mehrazar ${ }^{2}$
}

\begin{abstract}
Background: Currently, the efficient production of chimeric mice and their survival are still challenging. Recent researches have indicated that preimplantation embryo culture media and manipulation lead to abnormal methylation of histone in the H19/Igf2 promotor region and consequently alter their gene expression pattern. This investigation was designed to evaluate the relationship between the methylation state of histone $\mathrm{H} 3$ and $H 19 / \mathrm{Ig} 2$ expression in mice chimeric blastocysts.

Methods: Mouse 129/Sv embryonic stem cells (mESCs) expressing the green fluorescent protein (mESCsGFP) were injected into the perivitelline space of 2.5 days post-coitis (dpc) embryos (C57BL/6) using a micromanipulator. $\mathrm{H} 3 \mathrm{~K} 4$ and $\mathrm{H} 3 \mathrm{~K} 9$ methylation, and $\mathrm{H} 19$ and $\mathrm{Ig} 2$ expression was measured by immunocytochemistry and q-PCR, respectively, in blastocysts.

Results: Histone $\mathrm{H} 3$ trimethylation in $\mathrm{H} 3 \mathrm{~K} 4$ and $\mathrm{H} 3 \mathrm{~K} 9$ in chimeric blastocysts was significantly less and greater, respectively ( $\mathrm{p}<0.05$ ), than in controls. H19 expression was significantly less $(\mathrm{p}<0.05)$, while $I g f 2$ expression was less, but not significantly so, in chimeric than in control blastocysts.

Conclusions: Our results showed, that the alteration ofH3K4me3 and H3K9me3 methylation, change H19/Igf2 expression in chimeric blastocysts.
\end{abstract}

Keywords: Chimeric blastocysts, H19/Igf2, Histone 3 (H3) methylation.

\section{Introduction}

Chimeras are animals composed of two or more genetically different cell lineages or recipient embryos from the same or different species (1). Chimeric animals can give insights into the biological processes in the adults, including mechanisms underlying diseases or regenerative medicine (2-4). Currently, injection of embryotic stem cells (ESCs into the blastocysts is the most common technique to generate chimera mice (1). Previous studies showed that microinjection of ESCs into the blastocyst is an efficient approach to produce a good germ line-transmitted chimera
(5-7). In this regard, application of laser technology to help introduce ESCs into the perivitelline embryonic space has its own advantage to produce ESC-derived F0 chimaeras (1). Despite the advantages of chimeric mice in biological studies, the efficiency of generating and survival are still low.

Many studies have shown that manipulation of preimplantation embryos can cause birth defects including low birth weight, cardiovascular defects, congenital malformations, and abnormal placentation (8). 
Moreover, embryo manipulation and culture conditions can change early embryo development and gene expression patterns by modifying epigenetic factors (9). However, micromanipulation of embryos increases nonphysiological epigenetic profiles that lead to aberrant chromatin remodeling and genomic imprinting, which can result in genetic diseases including Beckwith-Wiedemann and Angelman syndromes (10-12).

Evidence indicates that some imprinting genes are predominantly expressed by the maternal, while others only by the paternal, chromosome (13). Currently, about 100 proteins encoded by imprinted genes have been identified in both mice and human genomes (14). In mice embryos, H19/Igf 2 imprinting genes have greater sensitivity to culture supplements and micromanipulations than other imprinted genes $(15,16)$. Also, H19/Igf2 have an essential function in the control of embryo development, placental organization, and fetal growth (17). A previous study observed that the abnormal imprinting of the H19/Igf2 genes arose from abnormal histone modifications and atypical DNA methylation at the imprinting control region (ICR) (18-20). Differential epigenetic modification at the ICR and upstream of the transcription site of the imprinting genes in the preimplantation embryo have been observed (21). For instance, lysine methylations restricted to the promoter of the imprinted loci are $\mathrm{H} 3$ lysine 9 trimethylation $(\mathrm{H} 3 \mathrm{~K} 9 \mathrm{me} 3)$ and $\mathrm{H} 3$ lysine 4 trimethylation (H3K4me3), which lead to inhibition and activation, respectively, of gene expression in imprinting genes (15). Recent studies have shown that embryo culture and manipulations, including cryopreservation, intracytoplasmic sperm injection (ICSI), and somatic cell nuclear transfer (SCNT) can lead to the abnormal histone methylation in promoter regions of the imprinting genes $(22,23)$. However, histone 3 methylation and H19/Igf2 expression has not yet been investigated in chimeric mice.

\section{Materials and methods} Animal and Chemical

The experimental animal model use for this study was created based on the guidelines of the
Research Ethics Committee of Shahid Beheshti University of Medical Sciences. All reagents were obtained from Sigma Chemical (St. Louis, USA), unless otherwise mentioned. Male and female C57BL/6 mice were obtained from the Pasteur institute, Tehran, Iran and housed in 50\% humidified and temperature-controlled rooms at 20-24 ${ }^{\circ} \mathrm{C}$ ) on a 12-hour light-dark cycle. All animals had free access to water and food.

\section{Experimental Groups}

$\mathrm{H} 3 \mathrm{~K} 9$ and $\mathrm{H} 3 \mathrm{~K} 4 \mathrm{H} 3$ histone methylation and the relative expression of the $\mathrm{H} 19$ and $\mathrm{Igf2}$ imprinting genes and were evaluated in the blastocysts of the following experimental groups: i. in vivo-derived blastocysts (blastocyst $/$ in vivo or control; $\mathrm{n}=60$ ), ii. blastocysts obtained from in vivo-derived morula (blastocyst/2.5 days' post coitum (dpc) embryo; $\mathrm{n}=60$ (, and iii. blastocysts obtained from in vivo-derived morula that had been subjected to subzonal mESCs injection (Blastocyst/chimeric; $\mathrm{n}=60$ ). Total embryos were collected and cultured from the three groups simultaneously at the same developmental stage.

\section{Collection of 2.5 days-post-coitis (dpc) embryos}

Female mice ( $\mathrm{n}=20$ C57BL/6), 8-10 weeks old, were superovulated with an intraperitoneal (IP) injection of $7.5 \mathrm{IU}$ of pregnant mare serum gonadotropin (PMSG; Folligon, Intervet); followed by $7.5 \mathrm{IU}$ of human chorionic gonadotropin (HCG; Novarel, Pregnyl) 46 to 48 hours later. These mice were then mated with C57BL/6 male mice. Females with vaginal plugs were euthanized by cervical dislocation at 2.5 dpc time and these embryos collected by oviduct flushing (24), transferred in a $30 \mu$ droplet of KSOM medium supplemented with amino acids (KSOMaa) (25), and incubated in a $37^{\circ} \mathrm{C}, 5 \%$ $\mathrm{CO}_{2}$, humidified atmosphere.

\section{Subzonal Injection of GFP-ESCs}

Mouse 129/Sv ESCs, labeled with GFP (GFPmESCs), were used for the subzonal injection. This line has been used for follow-up to ensure that the embryonic stem cells have integrated in the inner cell mass for chimeric formation. The GFP-mESCs were cultured in knockout DMEM 
(Invitrogen) supplemented with 15\% Knockout Serum (KOSR; Invitrogen, Gibco), 1\% MEM non-essential amino acids (Gibco), $2 \mathrm{mM}$ GlutaMAX, $\quad 100 \quad \mathrm{mM} \quad \beta$-mercaptoethanol (Gibco), $100 \mathrm{U} / \mathrm{ml}$ penicillin, $100 \mathrm{mg} / \mathrm{ml}$ streptomycin, $1000 \mathrm{U} / \mathrm{ml}$ mouse leukemia inhibitory factor (LIF, Pro Spec), 2\% ES-FBS (ES Cell Qualified FBS), R2i (1 $\mu$ M PD0325901 (Selleck, USA), and $10 \mu$ M SB431542 (Selleck, USA). The GFP-mESCs were cultured on 12well plates coated with sterile $0.1 \%$ gelatin. The cells were trypsinized at $70 \%$ confluency to gain a solution of single-cell suspension and maintained in ES cell medium supplemented with 0.2 M HEPES (26).

Next, 2.5 dpc, a laser beam (150 FU; Prime Tech Ltd, Tsuchiura-shi) was applied to the embryos' thin zona pellucidae. The inner surface of a 20 $\mu \mathrm{m}$ diameter injection needle was rinsed with $10 \%$ polyvinylpyrrolidone (PVP) and $15 \mathrm{mESCs}$ were injected into the embryos' $(n=60)$ subzonal spaces using a Narishige micromanipulator. The mESCs were injected in a medium containing $0.2 \mathrm{M}$ sucrose. The GFP-mESC-injected embryos were cultured in KSOMaa and incubated in a $37{ }^{\circ} \mathrm{C}, 6.5 \% \mathrm{CO}_{2}$, humidified atmosphere for 24 hours until the blastocyst stage (1). To ensure chimeric blastocyst formation, these blastocysts were observed under a fluorescent microscope to evaluate the incorporation of mESCs-GFP into the ICM and selected for immunocytochemistry and Real Time PCR.

\section{Immunofluorescence staining of H3K9me3 and $\mathrm{H} 3 \mathrm{~K} 4 \mathrm{~m} 3$}

Trimethylation of $\mathrm{H} 3 \mathrm{~K} 9$ and $\mathrm{H} 3 \mathrm{~K} 4$ in chimeric blastocysts was visualized by immunocytochemistry as previously described (27). Briefly, the zona pellucida was dissolved by Tyrode's acid (Sigma T1788; pH: 2.5) for 30 $\mathrm{sec}$ at room temperature, fixed by $4 \%$ paraformaldehyde for $30 \mathrm{~min}$ at $4{ }^{\circ} \mathrm{C}$, and permeabilized by $0.3 \%$ Triton X-100 for nearly 1 $\mathrm{h}$ at $4{ }^{\circ} \mathrm{C}$. The solution was blocked with $2 \%$ BSA/PBS for $40 \mathrm{~min}$ at $25{ }^{\circ} \mathrm{C}$ and then incubated overnight at $4{ }^{\circ} \mathrm{C}$ with primary antibodies against H3K9me3 (Abcam, Cambridge, MA, USA) diluted 1:200 and anti-
H3K4me3, also diluted 1:200 (Abcam, Cambridge, MA, USA) for $1 \mathrm{~h}$ at $25{ }^{\circ} \mathrm{C}$. After washing with PBS/PVA for $10 \mathrm{~min}$, the blastocysts were incubated with the secondary antibody, goat $\mathrm{F}\left(\mathrm{ab}^{\prime}\right) 2$ anti-mouse $\mathrm{IgG} \mathrm{H} \& \mathrm{~L}$ (PE/Cy5.5), at 1:500 in 2\% BSA/PBS for $90 \mathrm{~min}$ at $37^{\circ} \mathrm{C}$ (Abcam, Cambridge, MA, USA). After 3 rinses, the blastocyst nuclei were stained by 15 $\mu \mathrm{g} / \mathrm{mL}$ of 6-diamidino-2-phenylindole (DAPI) (CA, USA) for $10 \mathrm{~min}$ and all the samples were mounted on the slides with glycerol. Each assay was performed in triplicate and at least 40 blastocysts were analyzed for each group. The samples were evaluated through an epifluorescence microscope (Nikon, Tokyo, Japan) and immunofluorescence staining images obtained with a digital camera (HD1080p CMOS color camera, Euromex). The fluorescent images of the blastocysts were analyzed by the ImageJ software (Bethesda, MD).

\section{Gene Expression by Real-Time PCR RNA extraction}

Total RNA was extracted from 5 blastocysts by TRIzol reagent (Life Technologies, Gent, Belgium) based on the manufacturer's instructions. Briefly, the blastocysts were homogenized in $50 \mu \mathrm{l}$ of TRIzol, $25 \mu \mathrm{l}$ of chloroform were added to each sample, kept at $25{ }^{\circ} \mathrm{C}$ (room temperature; RT) for $5 \mathrm{~min}$, and centrifuged at $8000 \mathrm{~g}$ for $5 \mathrm{~min}$ at $4{ }^{\circ} \mathrm{C}$. The RNA was precipitated by adding isopropanol and then centrifuged at $8000 \mathrm{~g}$ for $5 \mathrm{~min}$. The supernatant was disposed, and the RNA washed with $80 \%$ ethanol. Total RNA was resuspended in $10 \mu \mathrm{l}$ of DEPC water and stored at $-80^{\circ} \mathrm{C}$.

\section{cDNA synthesis}

The RNA concentration was determined by a spectrophotometer (Picodrop, Real-Life). Complementary DNA (cDNA) was produced using a PrimeScript QuantiTect Kit (Qiagen, cat: 205310). All reactions were performed in $20 \mu \mathrm{l}$ volumes containing $2 \mu \mathrm{l}$ of genomic DNA (gDNA), $13 \mu \mathrm{l}$ of total RNA, $4 \mu \mathrm{l}$ of enzyme buffer, and $1 \mu \mathrm{l}$ of enzyme under the following thermocycling condition: $42{ }^{\circ} \mathrm{C}$ for $2 \mathrm{~min}, 42^{\circ} \mathrm{C}$ for $15 \mathrm{~min}$, and $95^{\circ} \mathrm{C}$ for $3 \mathrm{~min}$. The cDNAs were stored at $-20^{\circ} \mathrm{C}$ until used in quantitative PCR. 


\section{Quantitative reverse transcriptase PCR (qRT- PCR)}

The relative expression of $H 19$ and $I g f 2$ was determined by qRT-PCR using a Rotor-Gene Q instrument (Qiagen). All reactions were performed in $10 \mu \mathrm{l}$ volumes containing $5 \mu \mathrm{l}$ of SYBR Premix Ex Taq II reagent (Takara Bio), $0.2 \mu \mathrm{l}$ of each primer $(10 \mu \mathrm{M}), 2 \mu \mathrm{l}$ of cDNA template, and $2.6 \mu \mathrm{l}$ of $\mathrm{ddH} 2 \mathrm{O}$. The qPCR primers are listed in Table 1 . The program used for PCR amplification was $95{ }^{\circ} \mathrm{C}$ for $30 \mathrm{sec}$ as initiation, 50 cycles at $95{ }^{\circ} \mathrm{C}$ for $5 \mathrm{sec}$ as denaturation, $60{ }^{\circ} \mathrm{C}$ for $30 \mathrm{sec}$ as annealing/extension, and 60 to $95{ }^{\circ} \mathrm{C}$ with a ramp rate of $0.3{ }^{\circ} \mathrm{C} / \mathrm{s}$ as the melting curve. GAPDH and H2AFZ were used as internal controls and the samples' mRNA levels were normalized against them. Three replicates were performed for each group. The relative mRNA expression was evaluated by REST 2009 Software (Qiagen, Hilden, Germany).

Table 1. Primers used for real-time quantitative PCR.

\begin{tabular}{clc} 
& \multirow{2}{*}{ Primer sequences (5'-3') } & Tm \\
\hline \multirow{2}{*}{ Gapdh } & Forward: TTCCAGTATGATTCCACCCAC & 55.9 \\
& Reverse: ACTCAGCACCAGCATCACC & 55.7 \\
\hline \multirow{2}{*}{ H2afz } & Forward: CTCGTCTCTTCCTCGCTCGT & 61.3 \\
& Reverse: CGTCCGTGGCTGGTTGTC & 61.04 \\
\hline \multirow{2}{*}{ Igf2 } & Forward: TGTGAGCAAGCGACGGAGT & 58.3 \\
& Reverse: GGATTCAGTGGCTGGCAGA & 58.6 \\
\hline \multirow{2}{*}{$H 19$} & Forward: TGAAGGCGAGGATGACAGGT & 58.9 \\
& Reverse: TCCAGAGAGCAGCAGAGAAGTG & 60 \\
\hline
\end{tabular}

\section{Statistical Analysis}

The fluorescent intensity of histone methylation was analyzed using one-way ANOVA test (Tukey's post-hoc) and expressed as mean \pm SD. Analyses were performed using the SPSS statistical software, version 19 (Armonk, NY, USA). Differences were considered to be statistically significant at $\mathrm{p}<0.05$.

\section{Results}

\section{Immunocytochemistry}

We used the mESCs carrying a GFP repoter to allow the chimeric blastocysts monitoring in the integration or exclusion during of the chimaera formation (Fig. 1.A). The methylation of H3K4 and $\mathrm{H} 3 \mathrm{~K} 9$ in the blastocysts were visualized by immunocytochemistry (Fig. 1) and processed with using of Image $\mathbf{J}$ software. The levels of methylation were evaluated by antibodies against H3K4me3 (red) and H3K9me 3 (red). The DNA is counterstained with DAPI (blue) and the merged images of $\mathrm{H} 3 \mathrm{~K} 4 \mathrm{me} 3$ and $\mathrm{H} 3 \mathrm{~K} 9 \mathrm{me} 3$ with DNA are shown purple (Fig. 1). While no significant difference was seen between the two groups blastocyst/in vivo and blastocyst/2.5 (dpc) embryo, fluorescence intensity in the H3K4 chimeric blastocysts was significantly less than that of the other two groups, $(\mathrm{p}<0.05$, Fig. $2 \mathrm{~A})$.

In contrast, fluorescence intensity in the $\mathrm{H} 3 \mathrm{~K} 9$ blastocyst/2.5 (dpc) embryo was significantly greater than of blastocyst/in vivo, also, fluorescence intensity in the $\mathrm{H} 3 \mathrm{~K} 9$ chimeric blastocyst was significantly greater than that of other two groups ( $p<0.05$, Fig. 2A).

These results indicate that there are dramatic reduction and increasing histone $\mathrm{H} 3$ methylation in $\mathrm{H} 3 \mathrm{~K} 4$ and $\mathrm{H} 3 \mathrm{~K} 9$ during chimeric blastocysts production, respectively.

\section{Quantitative Gene Expression}

H19 expression was significantly less in chimeric blastocysts than of other two groups $(\mathrm{p}<0.05$, Fig. 2B), while no significant difference was observed between blastocyst/in vivo and blastocyst/2.5 dpc embryo. In contrast, IGF2 expression did not differ significantly between any of the 3 groups ( $p>0.05$, Fig. 2B). 

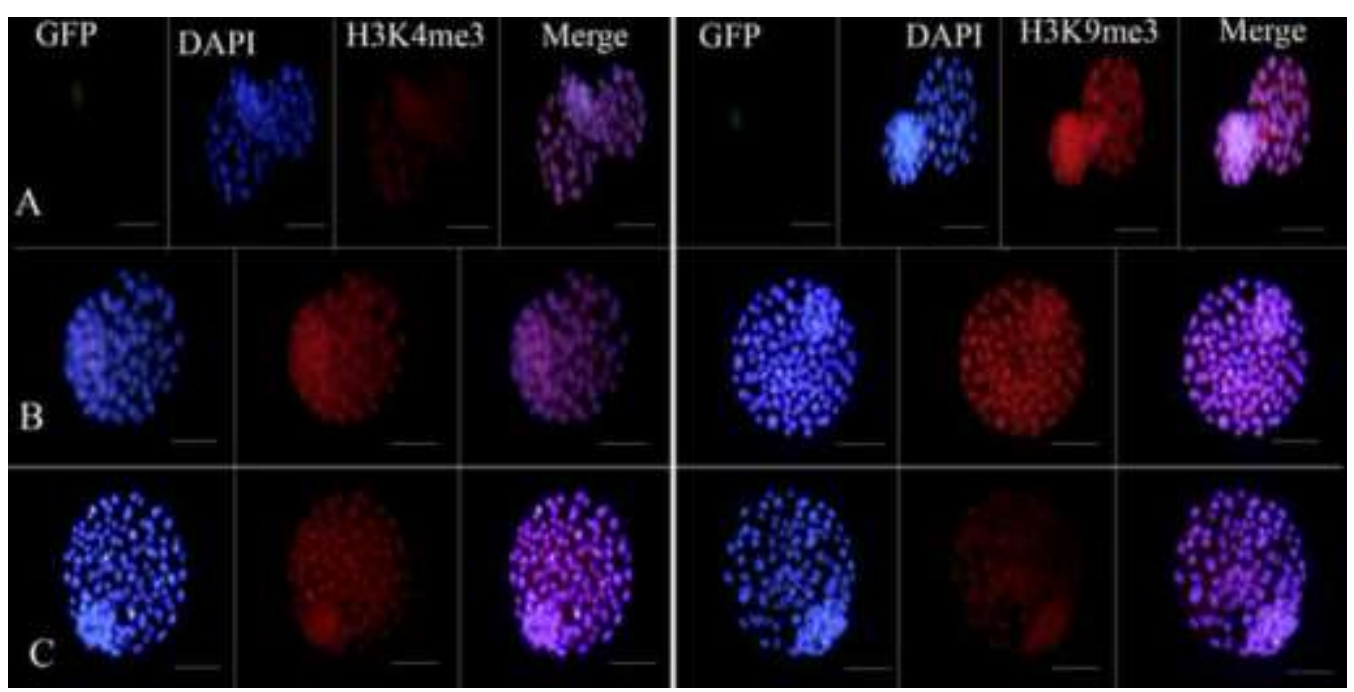

Fig. 1. Immunocytochemistry staining of H3K4me3 and H3K9me3 in chimeric blastocysts and blastocysts derived from other groups: (A): (Blastocyst/chimeric); B, Blastocyst/2.5 dpc embryo; C, Blastocyst/in vivo. The $\mathrm{mESCs}$ carrying green fluorescent protein (mESCsGFP) marker that allows all the chimeric blastocysts to be analyzed for integration (GFP, Green). The nuclei (blue) were stained with DAPI. H3K4me3 and H3K9me3 protein were stained with using anti-mouse IgG (red). The merged images of H3K4me3 and H3K9me3 with DNA are purple. Scale bars: $50 \mu \mathrm{m}$.

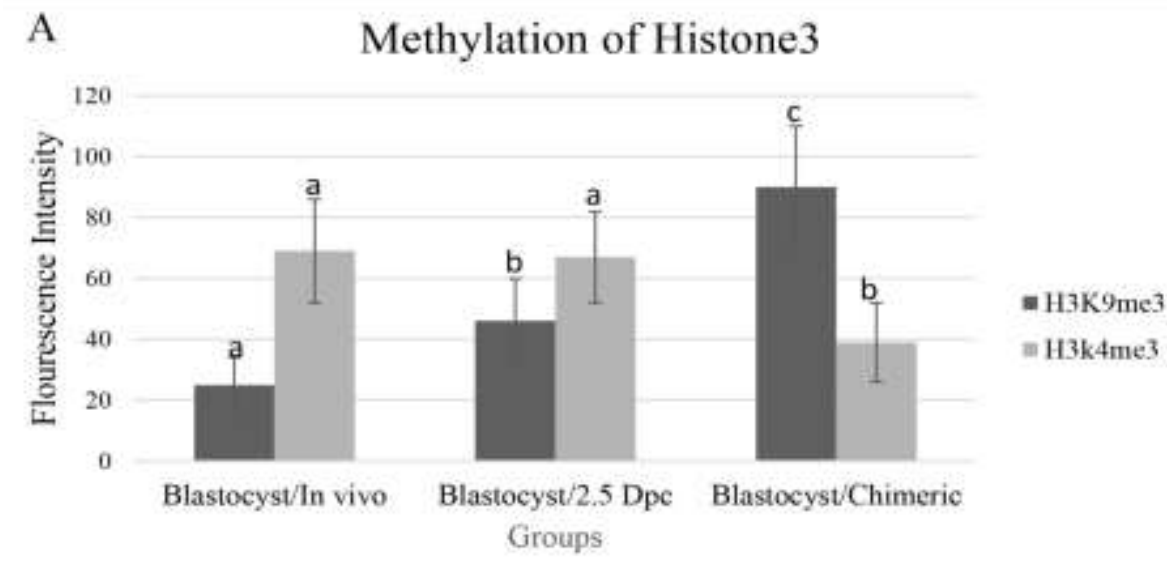

B

H19/ Igf2

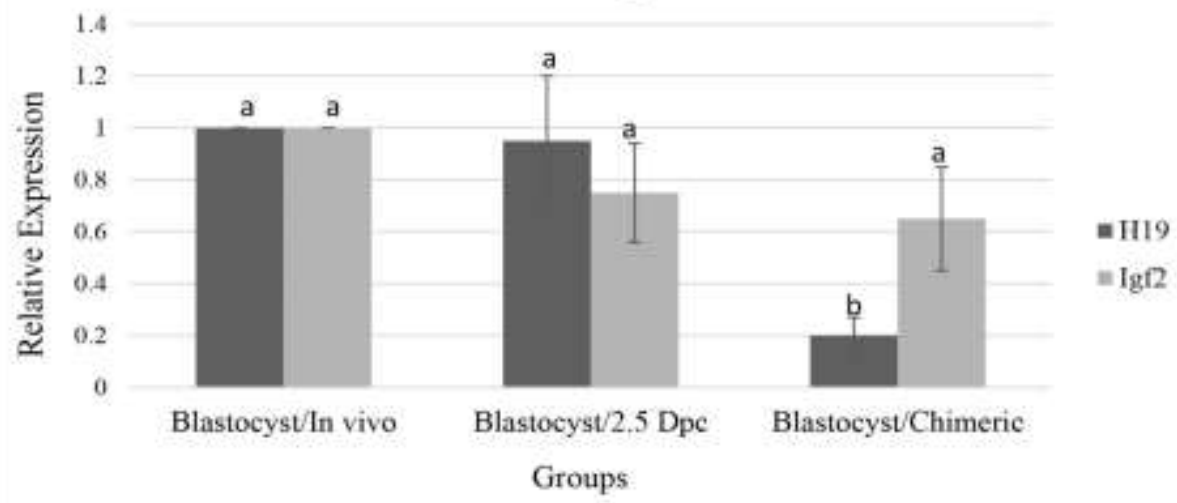

Fig. 2. Fluorescent intensities and relative gene expression in blastocysts; (A) H3K4me3 and H3K9me3 fluorescence intensity levels: Relative levels of global H3K9me3 and H3K4me3 in nucleus (mean \pm SEM). a/b values with different superscripts differ significantly ( $\mathrm{p}<0.05$ ) in relative levels of histone methylation were examined by Image-J software.; (B) H19 and Igf2 expression in the different blastocysts (Blastocyst/chimeric, Blastocyst/2.5 dpc embryo, Blastocyst/in vivo. Lower case letters a, b, and c above the bars represent statistical differences $(\mathrm{p}<0.05)$. Values are shown as means \pm SDs. 


\section{Discussion}

In vitro manipulation of embryo and culture conditions may lead to an increased risk of birth defects (8). Recent studies have shown that in vitro manipulations have a strong influence on embryo development and blastomeric arrangement (28). Embryo culture conditions can also affect preimplantation embryo quality as well as gene expression patterns through genetic and epigenetic modifications (29). Recent investigations showed that assisted reproductive technology (ATR) may lead to abnormalities in imprinting patterns that eventually lead to disorders in the fetus $(30,31)$.

Both $\mathrm{H} 19$ and $\mathrm{Igf} 2$ are critical regulatory genes involved in embryo development and morphology, feto-placental growth, and postnatal behavior (32). The maternallyexpressed allele of $\mathrm{H} 19$ is located in the imprinting regions of chromosomes 11 and 7 in humans and mice, respectively (33). Previous studies have demonstrated that H19 expression is influence by in vitro manipulations such as invitro fertilization (IVF) and SCNT (10).

This study assessed the effect of histone 3 methylation on $H 19$ and $I g f 2$ expression and showed a decrease in $H 19$ expression in chimeric blastocysts relative to controls. This might be due to epigenetic alterations in these genes' ICR. In agreement with our results, Khosla et al. demonstrated that embryo fertilization and specific medium (M16 medium) down-regulated H19 expression (34). Other studies indicated that IVF and Whitten's and KSOM media down-regulated H19 expression (35). However, Jahangiri et al. reported that vitrification of two-cell stage embryos had no effect on $H 19$ and MEST expression patterns (15). Nonetheless, most recent studies have demonstrated that some types of manipulation and embryo media may alter imprinting gene expression through DNA methylation and histone modifications (36).

It has been demonstrated that trimethylation of $\mathrm{H} 3 \mathrm{~K} 4$ and $\mathrm{H} 3 \mathrm{~K} 9$ change the activation of chromatin in the preimplantation embryo (37). It is also known that the H19 ICR has some methylation at histone $\mathrm{H} 3$ of $\mathrm{H} 3 \mathrm{~K} 4$ and $\mathrm{H} 3 \mathrm{~K} 9$
(35), so embryo micromanipulation and culture conditions can alter $\mathrm{H} 3 \mathrm{~K} 9 \mathrm{me} 3$ and $\mathrm{H} 3 \mathrm{~K} 4 \mathrm{me} 3$ methylation status in the H19 ICR (38).

$\mathrm{H} 3 \mathrm{~K} 4 \mathrm{me} 3$ has been enriched in the unmethylated allele of imprinting gene (39) and this was associated with transcription activation. $\mathrm{H} 3 \mathrm{~K} 4 \mathrm{me} 3$ is commonly enriched around the promoter sites that lead to activation of specific genes (40). In our study, H3K4 methylation in chimeric blastocysts decreased relative to the control groups; consequently, H19 expression was reduced in chimeric blastocysts. This result agrees with a study indicating that manipulation of in vitro-derived embryos can alter $\mathrm{H} 3 \mathrm{~K} 4 \mathrm{me} 3$ methylation and subsequent expression of imprinting genes (41).

$\mathrm{H} 3 \mathrm{~K} 9 \mathrm{me} 3$ that has been enriched in the methylated allele of imprinting gene is generally correlated with inactivation and reduced gene expression and heterochromatin formation (42, 43). In our study, we found a reverse relationship between $\mathrm{H} 3 \mathrm{~K} 9 \mathrm{me} 3$ and $\mathrm{H} 19$ expression in chimeric -blastocysts. Interestingly, the upregulation of $\mathrm{H} 3 \mathrm{~K} 9 \mathrm{me} 3$ decreased $\mathrm{H} 19$ expression in chimeric blastocysts relative to the in vivo obtained counterparts. Therefore, it seems the reduced H19 expression in chimeric blastocysts occurred due to down- and upregulation of $\mathrm{H} 3 \mathrm{~K} 4 \mathrm{me} 3$ and $\mathrm{H} 3 \mathrm{~K} 9 \mathrm{me} 3$ in their ICR site, respectively.

Igf2 is expressed specifically by the paternal allele under balanced conditions, so that $H 19$ for normal regulation of fetal and placental development is related to $I g f 2$ expression (44). $\mathrm{Li}$ et al. reported that supplemental media and in vitro fertilization lead to abnormalities in the DNA and histone methylation sites in the Igf2/H19 ICR (19). In the current study, despite decreased $I g f 2$ expression in chimeric blastocysts, its expression was not significantly different between the in vivo-derived blastocysts. This agrees with a study by Khosla et al. (35), in which manipulation and supplemental culture media changed Igf2 expression in mouse preimplantation embryos (35). Also, Igf2 expression in IVF, cloned, and vitrified blastocysts was less than that of in vivo 
blastocysts $(12,45)$. It should be noted, despite the reduced expression of $I g f 2$ in most previous studies, in our study Igf 2 expression in chimeric blastocysts was not significantly different from that of in vivo-derived blastocysts. Therefore, according to our study, it is likely that $I g f 2$ expression has been influenced by various factors including embryo micromanipulation, interaction of injected mESCs with embryo blastomeres, and supplementation of culture medium with BSA and non-essential amino acids. In this regard, in the chimeric blastocysts, down- and up-regulation of $\mathrm{H} 3 \mathrm{~K} 4 \mathrm{me} 3$ and $\mathrm{H} 3 \mathrm{~K} 9 \mathrm{me} 3$ in the ICR may be related to the reduced $\mathrm{H} 19$ and partially-reduced Igf 2 expression.

In this study, the chimeric blastocysts had abnormal H3K9me3 and H3K4me3 levels, which

\section{References}

1. Poueymirou WT, Auerbach W, Frendewey D, Hickey JF, Escaravage JM, Esau L, et al. F0 generation mice fully derived from gene-targeted embryonic stem cells allowing immediate phenotypic analyses. nature biotechnology. 2007;25:91-99.

2. Tam PP, Rossant J. Mouse embryonic chimeras: tools for studying mammalian development. Development. 2003 Dec;130(25):6155-63.

3. Mak TW. Gene targeting in embryonic stem cells scores a knockout in Stockholm. Cell. 2007;131(6):1027-1031.

4. Behringer RR. Human-animal chimeras in biomedical research. Cell Stem Cell. 2007;1(3):259-62.

5. Lee K-H. Methods to generate chimeric mice from embryonic stem cells. Embryonic Stem CellsBasic Biology to Bioengineering. 2011.

6. De Repentigny Y, Kothary R. Production of mouse chimeras by injection of embryonic stem cells into the perivitelline space of one-cell stage embryos. Transgenic Res. 2010;19(6):1137-44.

7. Saburi S, Azuma S, Sato E, Toyoda Y, Tachi C. Developmental fate of single embryonic stem cells microinjected into 8-cell-stage mouse embryos. Differentiation. 1997;62(1):1-11.

8. Khosla S, Dean W, Reik W, Feil R. Culture of preimplantation embryos and its long-term effects on gene expression and phenotype. Hum Reprod Update. 2001;7(4):419-27. led to reduced expression of the imprinting genes $\mathrm{H} 19$ and $\mathrm{Igf2}$, with $\mathrm{H} 19$ expression being significantly more decreased than Igf 2 .

\section{Acknowledgements}

The authors the faculty of the Shahid Beheshti, University of Medical Sciences, Tehran, Iran, and Reproductive Biotechnology Research Center, Avicenna Research Institute (ACECR), for providing the possibility of doing the study and their technical supports and University of Medical Sciences for helpful assistance.

This research received no specific grant from funding agencies in the public, commercial, or not-for-profit sectors.

The authors declare no conflict of interest.

9. De Rycke M, Liebaers I, Van Steirteghem A. Epigenetic risks related to assisted reproductive technologies: risk analysis and epigenetic inheritance. Hum Reprod. 2002;17(10):2487-94.

10. Urrego R, Rodriguez-Osorio N, Niemann H. Epigenetic disorders and altered gene expression after use of assisted reproductive technologies in domestic cattle. Epigenetics. 2014;9(6):803-15.

11. Eroglu A, Layman LC. Role of ART in imprinting disorders. Semin Reprod Med. 2012;30(2):10.

12. El Hajj N, Haaf T. Epigenetic disturbances in in vitro cultured gametes and embryos: implications for human assisted reproduction. Fertil Steril. 2013;99(3):632-41.

13. Cassidy FC, Charalambous M. Genomic imprinting, growth and maternal-fetal interactions. J Exp Biol. 2018;221(Pt Suppl 1):jeb164517.

14. Williamson CM, Blake A, Thomas S, Beechey CV, Hancock J, Cattanach BM, and Peters J (2013), MRC Harwell, Oxfordshire. World Wide Web Site - Mouse Imprinting Data and References http://www.har.mrc.ac.uk/research/genomic_impri nting/.

15. Jahangiri M, Shahhoseini M, Movaghar B. H19 and MEST gene expression and histone modification in blastocysts cultured from vitrified and fresh two-cell mouse embryos. Reprod Biomed Online. 2014;29(5):559-66. 
16. Park C-H, Uh K-J, Mulligan BP, Jeung E-B, Hyun S-H, Shin T, et al. Analysis of imprinted gene expression in normal fertilized and uniparental preimplantation porcine embryos. PloS One. 2011;6(7):e22216.

17.Koukoura O, Sifakis S, Spandidos DA. DNA methylation in the human placenta and fetal growth (Review). Mol Med Rep. 2012;5(4):883-889

18. Hur SK, Freschi A, Ideraabdullah F, Thorvaldsen JL, Luense LJ, Weller AH, et al. Humanized H19/Igf2 locus reveals diverged imprinting mechanism between mouse and human and reflects Silver-Russell syndrome phenotypes. Proc Natl Acad Sci U S A. 2016;113(39):10938-43.

19. Li T, Vu TH, Ulaner GA, Littman E, Ling J-Q, Chen H-L, et al. IVF results in de novo DNA methylation and histone methylation at an Igf2H19 imprinting epigenetic switch. Mol Hum Reprod. 2005;11(9):631-40.

20. Maupetit-Méhouas S, Montibus B, Nury D, Tayama C, Wassef M, Kota SK, et al. Imprinting control regions (ICRs) are marked by mono-allelic bivalent chromatin when transcriptionally inactive. Nucleic Acids Res. 2015;44(2):621-35.

21. Lin S. Roles of Protein Factors in Regulation of Imprinted Gene Expression. 2011.

22. Wang Z, Xu L, He F. Embryo vitrification affects the methylation of the H19/Igf2 differentially methylated domain and the expression of $\mathrm{H} 19$ and Igf2. Fertil Steril. 2010;93(8):2729-33

23. Franco MM, Prickett AR, Oakey RJ. The role of CCCTC-binding factor (CTCF) in genomic imprinting, development, and reproduction. Biology of Reproduction. 2014;91(5):1-9.

24. Vasudevan K, Sztein J. In vitro fertility rate of 129 strain is improved by buserelin (gonadotropinreleasing hormone) administration prior to superovulation. Lab Anim. 2012;46(4):299-303.

25. Ho Y, Wigglesworth K, Eppig JJ, Schultz RM. Preimplantation development of mouse embryos in KSOM: augmentation by amino acids and analysis of gene expression. Mol Reprod Dev. 1995;41(2):232-238.

26. Guo J, Wu B, Li S, Bao S, Zhao L, Hu S, et al. Contribution of mouse embryonic stem cells and induced pluripotent stem cells to chimeras through injection and coculture of embryos. Stem Cell Int. 2014;2014:409021.

27. Salimi M, Shirazi A, Norouzian M, Mehrazar MM, Naderi MM, Shokrgozar MA, et al. Histone Modifications of H3K4me3, H3K9me3 and Lineage Gene Expressions in Chimeric Mouse Embryo. Cell J. 2020;22(1):96-105.

28. Koustas G, Sjoblom C. Minute changes to the culture environment of mouse pre-implantation embryos affect the health of the conceptus. Asian Pacific Journal of Reproduction. 2016;5(4):287294.

29. Swain JE, Carrell D, Cobo A, Meseguer M, Rubio C, Smith GD. Optimizing the culture environment and embryo manipulation to help maintain embryo developmental potential. Fertil Steril. 2016;105(3):571-587.

30. Manipalviratn S, DeCherney A, Segars J. Imprinting disorders and assisted reproductive technology. Fertil steril. 2009;91(2):305-15.

31. Uyar A, Seli E. The impact of assisted reproductive technologies on genomic imprinting and imprinting disorders. Curr Opin Obstet Gynecol. 2014;26(3):210-221.

32. Plasschaert RN, Bartolomei MS. Genomic imprinting in development, growth, behavior and stem cells. Development. 2014;141(9):1805-13.

33. Schulz R, Menheniott TR, Woodfine K, Wood AJ, Choi JD, Oakey R. Chromosome-wide identification of novel imprinted genes using microarrays and uniparental disomies. Nucleic Acids res. 2006;34(12):e88-e88.

34. Khosla S, Dean W, Brown D, Reik W, Feil R. Culture of preimplantation mouse embryos affects fetal development and the expression of imprinted genes. Biol Reprod. 2001;64(3):918-926.

35. Doherty AS, Mann MR, Tremblay KD, Bartolomei MS, Schultz RM. Differential effects of culture on imprinted H19 expression in the preimplantation mouse embryo. Biol Reprod. 2000;62(6):1526-35.

36. Fedoriw A, Mugford J, Magnuson T. Genomic imprinting and epigenetic control of development. Cold Spring Harb Perspect Biol. 2012;4(7):a008136.

37. Ribeiro-Mason K, Boulesteix C, Brochard V, Aguirre-Lavin T, Salvaing J, Fleurot R, et al. Nuclear dynamics of histone $\mathrm{H} 3$ trimethylated on 
lysine 9 and/or phosphorylated on serine 10 in mouse cloned embryos as new markers of reprogramming? Cell Reprogram. 2012;14(4):283-294.

38. Ren Y-X, Chang W, Qiao J. Epigenetic Modification in Oocyte and reimplantation Embryonic Development. ReprodDevelop Med. 2017;1(1):13-17.

39. Dindot SV, Person R, Strivens M, Garcia R, Beaudet AL. Epigenetic profiling at mouse imprinted gene clusters reveals novel epigenetic and genetic features at differentially methylated regions. Genome Res. 2009;19(8):1374-83.

40. Zhang B, Zheng H, Huang B, Li W, Xiang Y, Peng X, et al. Allelic reprogramming of the histone modification $\mathrm{H} 3 \mathrm{~K} 4 \mathrm{me} 3$ in early mammalian development. Nature. 2016;537(7621):553-557. 41. Nichols J, Zevnik B, Anastassiadis K, Niwa H, Klewe-Nebenius D, Chambers I, et al. Formation of pluripotent stem cells in the mammalian embryo depends on the POU transcription factor Oct4. Cell. 1998;95(3):379-391.
42. Chantalat S, Depaux A, Héry P, Barral S, Thuret JY, Dimitrov S, Gérard M. Histone H3 trimethylation at lysine 36 is associated with constitutive and facultative heterochromatin. Gen Res. 2011; 21(9):1426-37.

43. Pannetier M, Julien E, Schotta G, Tardat M, Sardet C, Jenuwein T, Feil R. PR-SET7 and SUV4-20H regulate $\mathrm{H} 4$ lysine-20 methylation at imprinting control regions in the mouse. EMBO Rep. 2008;9(10):998-1005.

44. Moore GE, Ishida M, Demetriou C, Al-Olabi L, Leon LJ, Thomas AC, Abu-Amero S, Frost JM, Stafford JL, Chaoqun Y, Duncan AJ. The role and interaction of imprinted genes in human fetal growth. Philosophical Transactions of the Royal Society B: Biologic Sci. 2015 5;370(1663):20140074.

45.Wang Z, Xu L, He F. Embryo vitrification affects the methylation of the H19/Igf2 differentially methylated domain and the expression of $\mathrm{H} 19$ and Igf2. Fertil Steril. 2010;93(8):2729-33. 